\title{
Damage, Lifetime, and Repair of Forging Dies
}

\author{
Bruno Buchmayr \\ Lehrstuhl für Umformtechnik, Montanuniversität Leoben, Leoben, Austria
}

Received November 22, 2016; accepted November 29, 2016; published online December 14, 2016

\begin{abstract}
The life time of forging dies is essential for economic production. The forging conditions and the characteristic tool damage vary from part to part, which makes a life time prediction very difficult. By means of three case studies, it is shown that the knowledge of the dominant damage mechanism is the key to finding out proper counter-measures or repair technologies. Best practice processing and repair technologies are discussed in this paper. Common tool materials are listed and assigned to their proper usage. Plasma-nitriding without white layer is proposed to be a good economic and technical compromise, when compared to other surface technologies. Finally, the potential of automatic tooling for die repair is pointed out.
\end{abstract}

Keywords: Closed-die forging, Damage mechanisms, Die repair methods, Tool life

Schädigung, Lebensdauer und Reparatur von Schmiedegesenken

Zusammenfassung: Die Lebensdauer von Schmiedewerkzeugen ist für eine wirtschaftlich erfolgreiche Produktion von hoher Bedeutung. Da die Schmiedebedingungen und die charakteristische Werkzeugschädigung von Teil zu Teil doch sehr unterschiedlich ausgeprägt sind, ist auch die Lebensdauervorhersage mit hoher Unsicherheit verbunden. Anhand von drei Fallbeispielen wird gezeigt, dass das Erkennen des dominant wirksamen Schädigungsmechanismus ein Schlüssel ist, um geeignete Gegenmaßnahmen bzw. Reparaturmethoden zu finden. Praxiserprobtes Vorgehen und neue Entwicklungen in der Wartung von Werkzeugen werden hier dargestellt. Übliche Werkzeugwerkstoffe werden je nach typischen Anwendungsanforderungen aufgezählt. Im Vergleich zu anderen Oberflächentechnologien hat sich das Plasma-Nitrieren ohne weiße Verbindungs-

\footnotetext{
Univ. Prof. Dipl.-Ing. Dr. B. Buchmayr $(\varangle)$

Lehrstuhl für Umformtechnik,

Montanuniversität Leoben,

Franz-Josef-Str. 18,

8700 Leoben, Austria

Bruno.Buchmayr@unileoben.ac.at
}

schicht weit etabliert. Schließlich werden auch die Potentiale für automatische Reparaturtechniken angesprochen.

Schlüsselwörter: Gesenkschmieden,

Schädigungsmechanismen, Gesenkreparatur, Lebensdauer

\section{Introduction}

Due to the fact that 10 to $30 \%$ of the total costs of hot forged components are related to the forging die manufacturing, it is essential to consider powerful and economical repair technologies to increase the lifetime of hot forging dies. Important factors for the lifetime of forging dies include die material, die design, die manufacturing parameters, and forging conditions which may influence the corresponding type of failure or damage. Depending on the operation conditions and dominant damage mode, the relevant criteria for the selection of proper surface conditions and hard facing alloys are considered. Best practice repair technologies, like HSC machining, hard facing using dissimilar materials, thin vapor depositions (CVD, PVD), and special surface technologies as well as hybrid solutions, are considered regarding their characteristic properties. Similar and dissimilar consumables, like chromium carbide systems, nickel base alloys, Co-based stellites, and multi-layer coatings, are also taken into account.

\section{Typical Failure Appearance of Forging Dies}

During closed-die forging, dies are exposed to complex thermo-mechanical loading conditions [1]. The requirements for forging dies include:

- High wear resistance at high temperatures

- Good form stability

- High die life time

- Good weldability (for repair)

- High thermal conductivity 
Fig. 1: Temperature-time-cycle during forging [1]

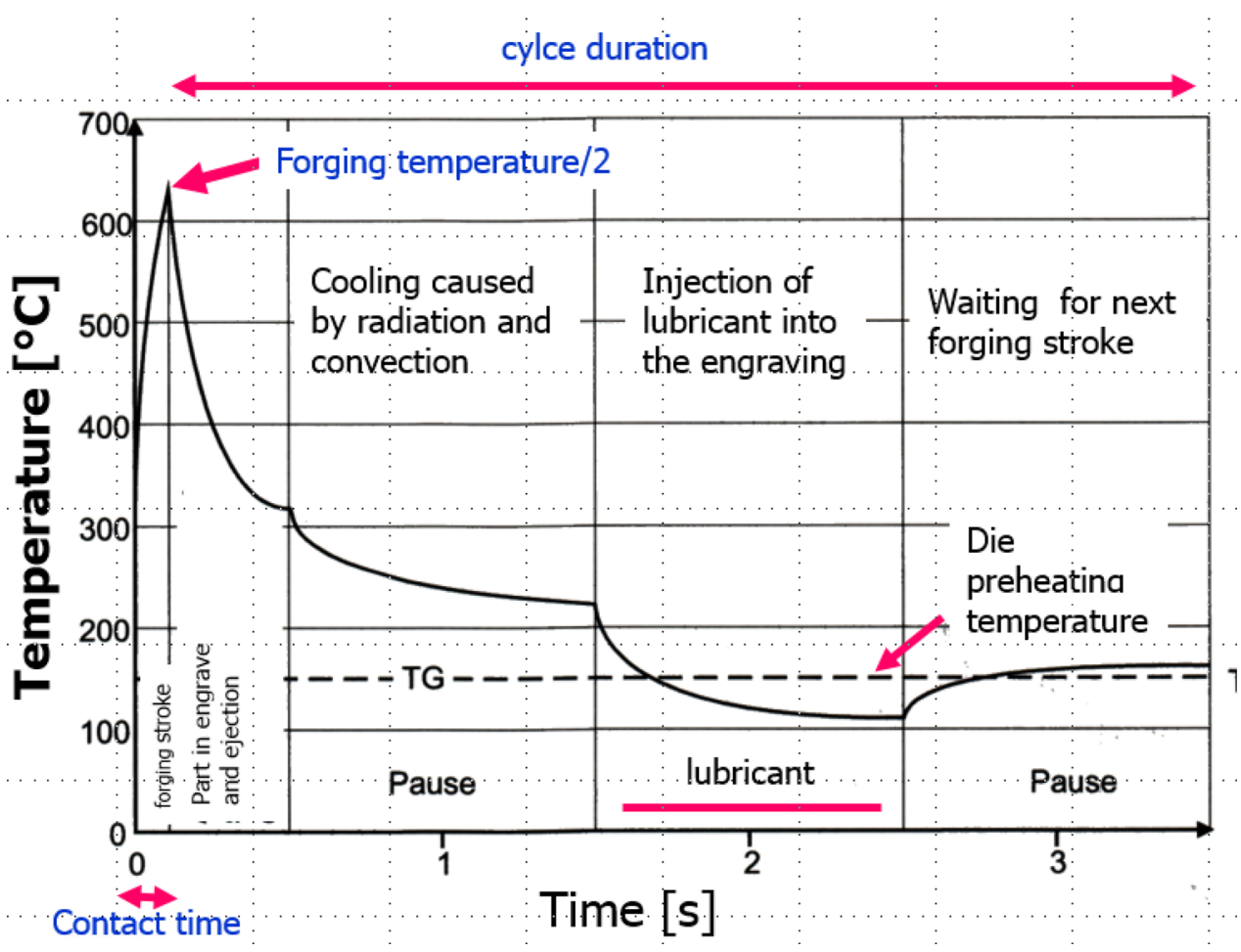

Fig. 2: Appearance of two closed-die forging dies after about 10,000 cycles [4]
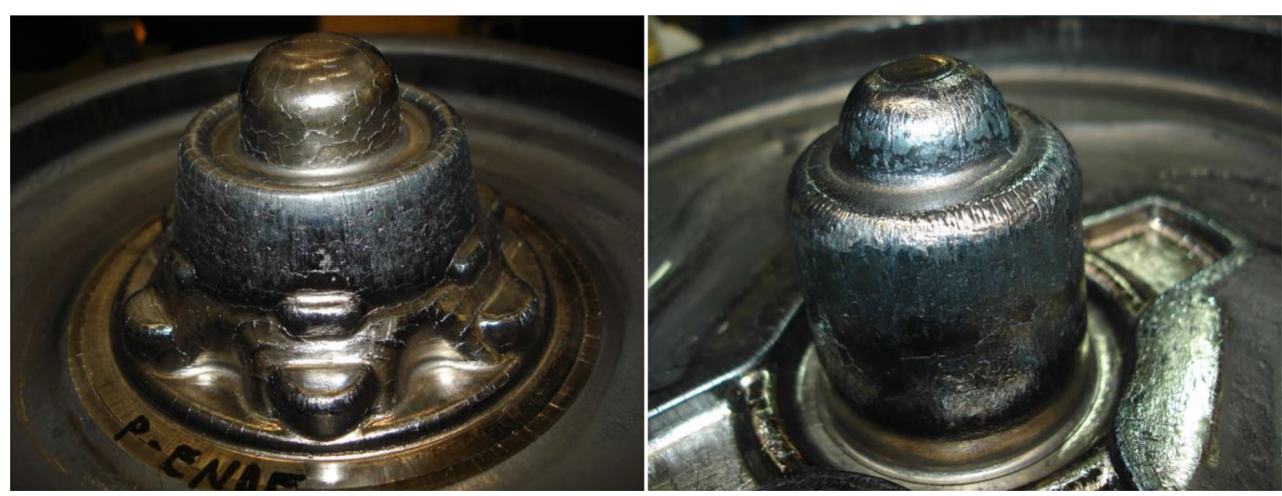

- Optimal surface hardness (40-44 HRC)

- Economic repair possibility

During the contact time, the surface temperature can reach about $700^{\circ} \mathrm{C}$ followed by cooling due to radiation and convection in air and by water cooling. A typical temperature history is shown in Figure 1.

Depending on the local value of the most important parameters, like velocity of material flow, contact stress, contact time, local temperature as well as hardness and toughness of the tool steel, may influence the tool performance. Suitable hot work tool steels are designed to achieve high-temperature strength, wear resistance, toughness, and tempering resistance $[2,3]$. Due to the fact that some parameters behave in opposite direction, there are different hot working tool steels with special profiles of the aforementioned required properties to avoid abrasion, mechanical cracking, thermal cracking, and plastic deformation. Among the failure modes, abrasive wear, which takes places in about $70 \%$ of all cases, is the most important failure mode.

\section{Some Damage Modes in Practice}

Three cases are described.

\subsection{Case 1}

Figure 2 shows two worn forging dies after about 10,000 strokes [4]. Although the tool steel is the same in both cases, it is obvious that the dominant damage mechanism is slightly different, which can only be explained by differences in the local loading conditions. On the left hand side, thermal fatigue was dominant, whereas the die on the right hand side has predominantly seen abrasion. Therefore, the measures to improve the whole situation also has to be set 
Fig. 3: Damaged ejector with cross sections of cracking field and remaining fracture area

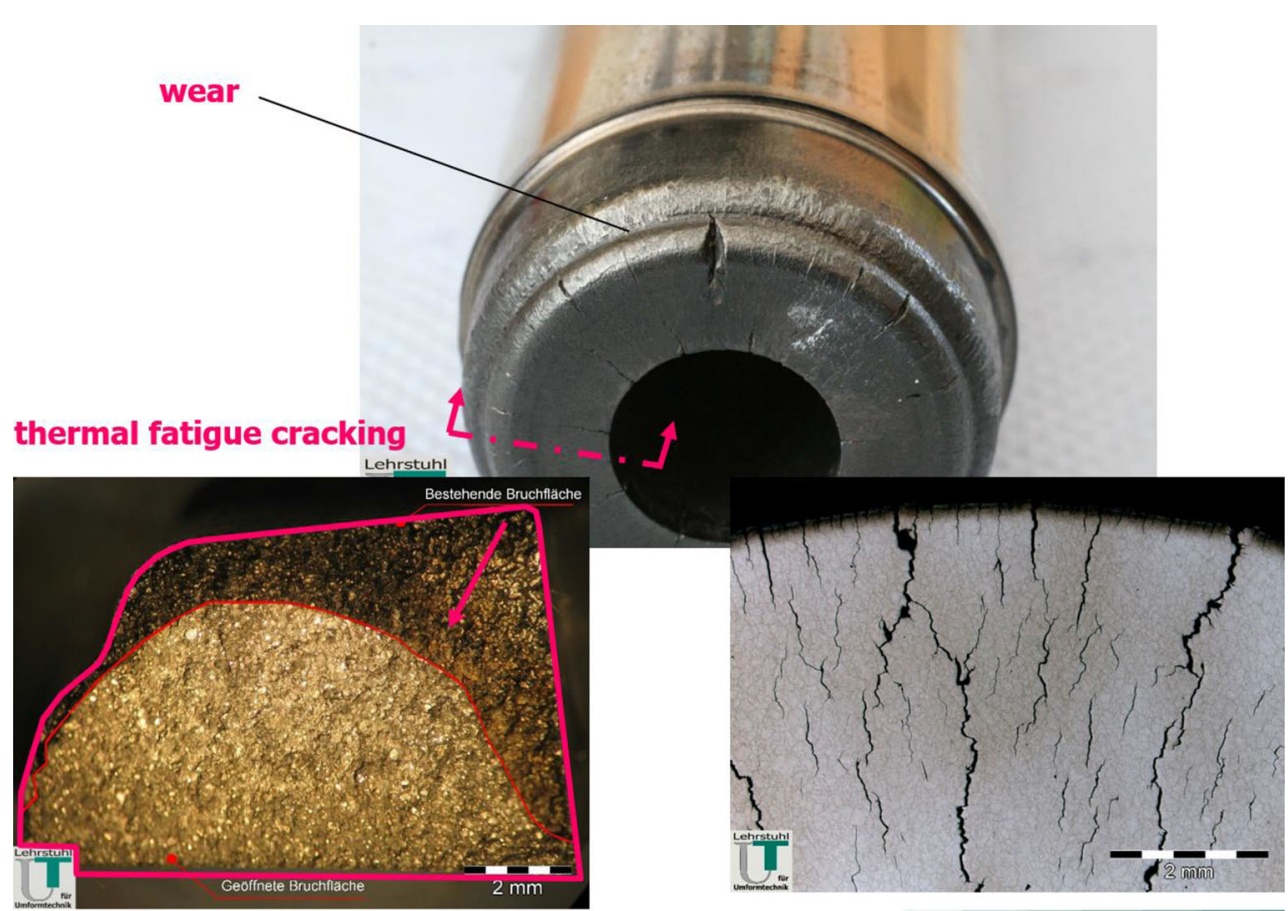

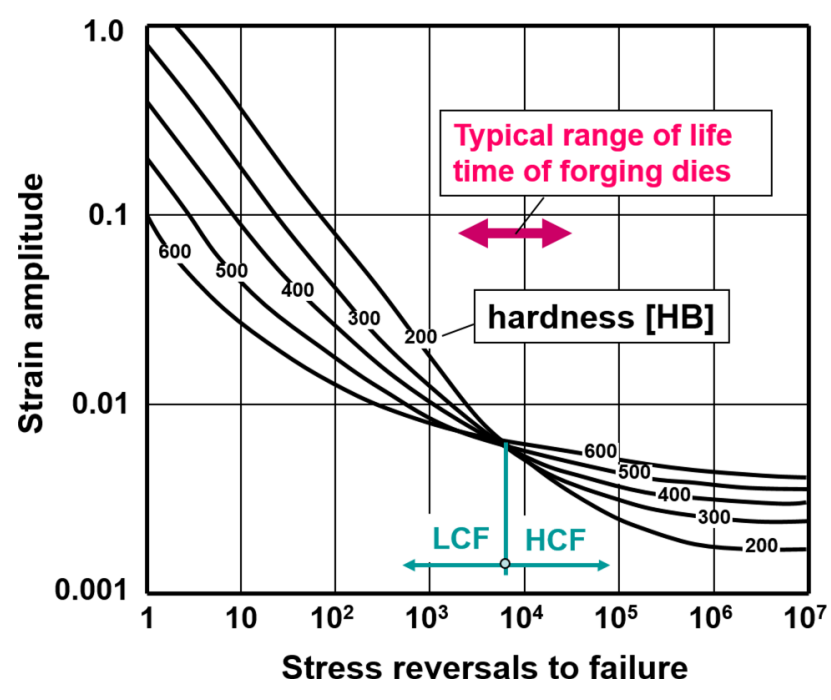

Fig. 4: Influence of hardness on the fatigue behaviour showing only small effects at medium life times [5]

in dependence on the damage mechanism. Even in one die, different failure mechanisms can occur, i.e. different worn locations need different surface treatments.

\subsection{Case 2}

The macroscopic view of a damaged ejector of a hot forming press (Hatebur machine) is shown in Figure 3 in combination with a cross section of the multiple cracking appearance and the cracked and remaining residual fracture area. Thermal shock and the resulting thermal stresses would lead to multiple cracks.
By searching proper counter-measurements to improve the die life time, we usually ask whether we should increase hardness or ductility. By consideration of a Manson-Coffindiagram, the dilemma of restricted changeability becomes visible. Figure 4 shows the influence of hardness on the fatigue behaviour, i.e. in the low-cycle fatigue range, ductility is more important, whereas, in the high cycle fatigue range, strength becomes important. In the typical range of a forging die life - the intermediate range -, we observe almost no influence of hardness on the life time. Now, it becomes evident that different measures using different surface technologies do not show a dramatic change of the life time situation at all.

\subsection{Case 3}

In this case, which is similar to Case 2, an ejector of a horizontal high speed forging machine shows a complete different surface appearance at the contact area, as shown in Figure 5 together with the microstructural section and hardness profile from the outer surface to the core. The morphology gives some evidence of overheating. The microstructure in the outer region is martensitic, and the hardness profile shows that at Position 4 there is a transition from an over-tempered structure to a newly formed martensitic layer.

Due to the metallic contact, the surface temperature can reach up to $700^{\circ} \mathrm{C}$. It is the mean temperature between preheating and forging temperatures under the assumption that the thermo-physical properties of the die and the forged part materials are similar. This can be verified by some annealing tests using different temperatures and times. Figure 6 shows such results, and, compared to the data in Figure 5, it can be confirmed that the above 


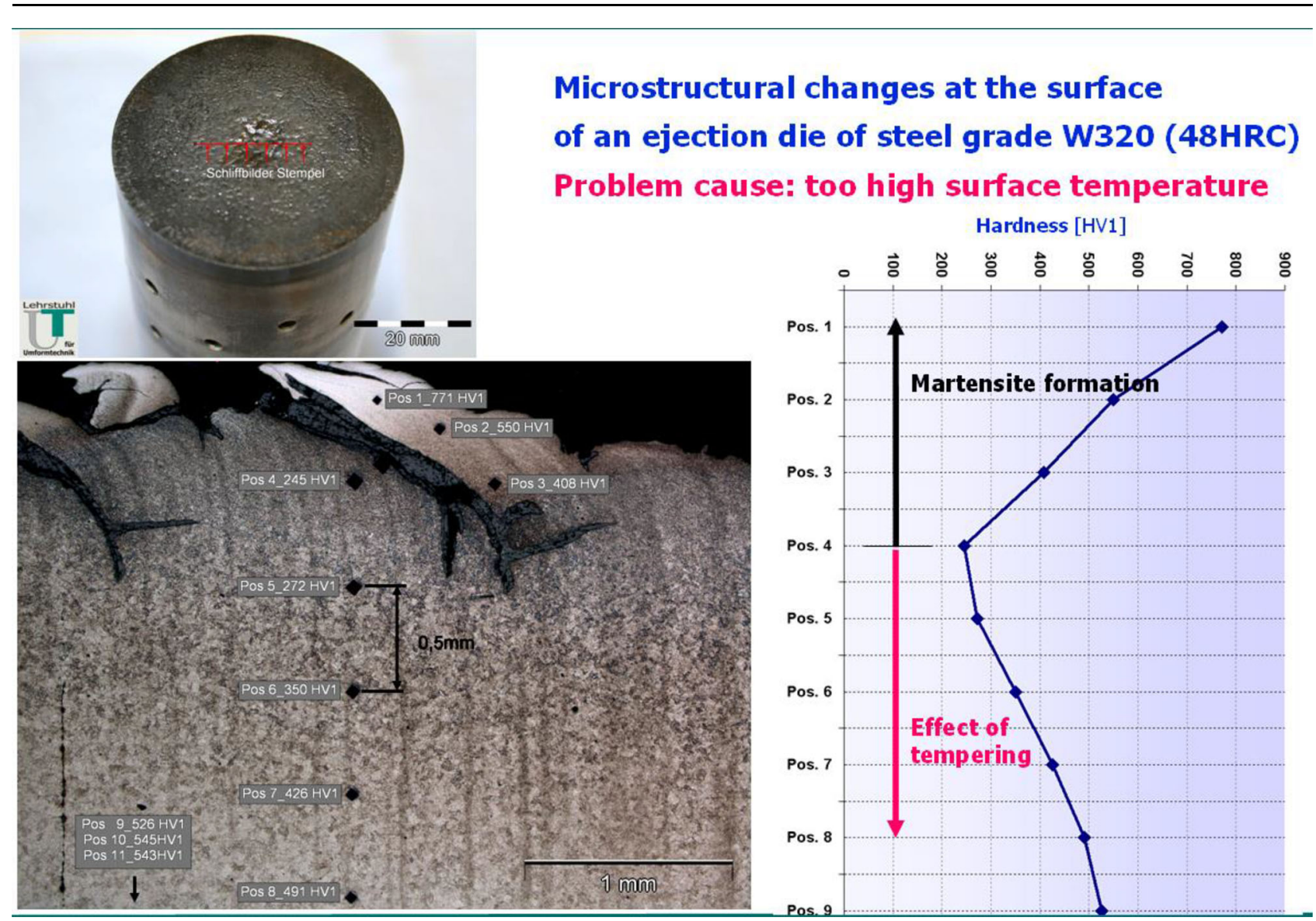

Fig. 5: Damage and microstructure of an ejection die after 17,000 strokes

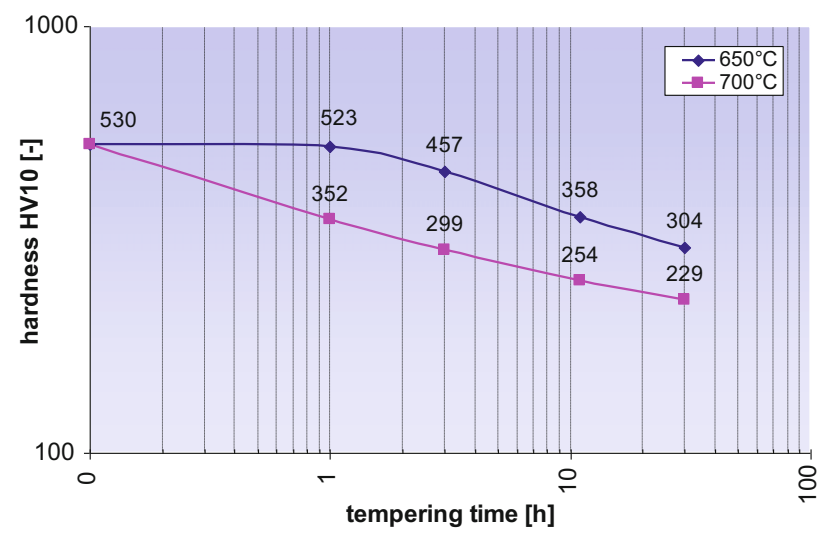

Fig. 6: Hardness loss due to tempering of hot working tool steel W320

mentioned contact temperature has been exceeded at the interface. Only intermediate layers having a low thermal conductivity, like Nickelbase-alloys or nitriding, are good counter-remedies to lower the contact temperature.

\section{Lessons Learned from the Case Studies}

- The degree of damage is very much dependent on the actual and local processing conditions.
- A specific measure can be positive for one kind of damage, but may be counter-productive regarding other damaging forms. There is a need to consider the counteractive interactions.

- Remedial actions are quite successful when there is only one dominant damage mechanism (i.e. hardness increase in case of mainly wear loading).

- Within the transition range LCF - HCF, there is only a small effect on the life time by chances in strength or ductility. Therefore, very large effects on life time improvements should not be expected.

- Apart from the mechanical tool properties, there is a strong effect of crystal structure and interface surface energy on the performance, especially in the case of adhesion.

To avoid cracks and wear of forging dies, some hints can be helpful:

- Homogeneous die-preheat to about $280^{\circ} \mathrm{C}$

- Intensive cooling to avoid die base temperatures of more than $300^{\circ} \mathrm{C}$

- Use of optimal isolating lubricants to avoid contact temperature at the interface of more than $650^{\circ} \mathrm{C}$ 


\begin{tabular}{|llll|}
\hline $\begin{array}{l}\text { TABLE 1 } \\
\text { Steel grades which are commonly used for forging dies }\end{array}$ \\
\hline Steel grade & Mat. No. & ANSI & \multicolumn{2}{l|}{ Typical Applications } \\
\hline 55NiCrMoV6 & 1.2713 & $6 F 2$ & \begin{tabular}{l} 
Hammer drop forging for small and medium sizes \\
\hline 56NiCrMoV7
\end{tabular} \\
\hline 57NiCrMoV 7 7 & 1.2714 & & $\begin{array}{l}\text { Hammer drop forging of large dimensions, geometric complex } \\
\text { engravings or inserts }\end{array}$ \\
\hline X38CrMoV 5 1 & 1.2744 & & Forging dies for hammers \\
\hline X40CrMoV 5 1 & 1.2343 & H11 & Conventional forging dies, tools for presses \\
\hline X32CrMoV 3 3 & 1.2344 & H13 & As H11, but a higher hot wear resistance \\
\hline X40CrMoV 5 3 & 1.2365 & H10 & Forging dies with good toughness for smaller parts \\
\hline X30WCrV 5 3 & 1.2367 & & Similar to 1.2365 \\
\hline
\end{tabular}

Fig. 7: Typical repair methods used for forging dies [4]

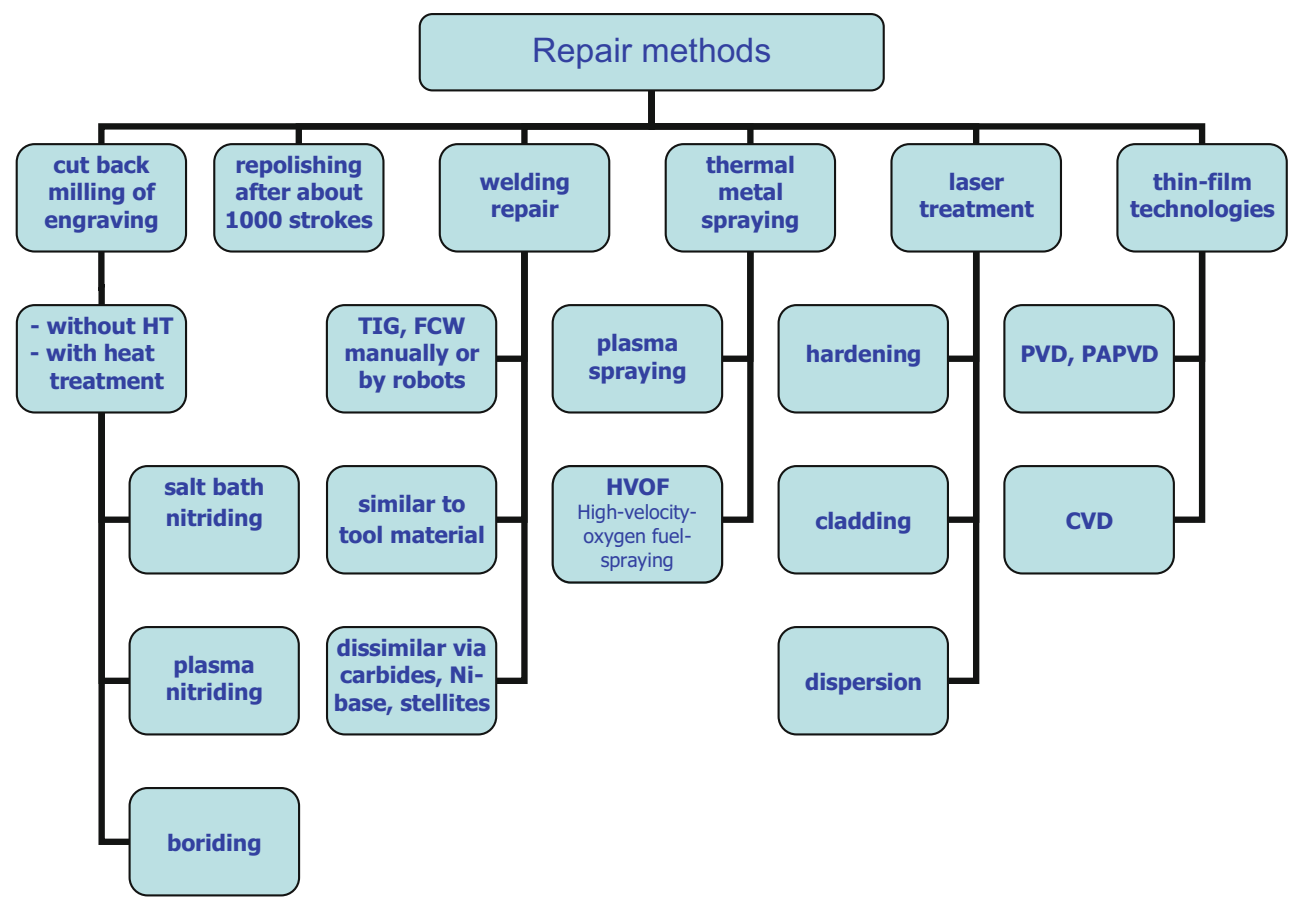

- Reduction of contact time by optimal ejection technique

- Sufficient long cooling phase between the strokes

Common forging die materials are shown in Table 1.

\section{Typical Repair Methods Applied to Worn Forging Dies}

As described in $[4,6]$, there are several repair methods in practical use to prolong the life time of tools or to reduce tooling costs. Depending on the actual wear mechanism, hard coatings including nitriding are proper means to increase the abrasion resistance, whereas Stellites are better for high thermal loading. An overview of the repair technologies in practical use is shown in Figure 7.

The workflow for maintenance of dies comprise the following steps:
- Contour-Measurement and consequent local material removal

- Removing of worn surfaces (gouging, HSC)

- Buttering (welding using multi-layer TIG, FW, or Laser metal deposition)

- HSC-Post processing or EDM

- Post welding Heat Treatment (Nitriding, PVD/CVD, or hybride coating)

Fundamentally, the following influencing factors have to be taken into account during the selection of a proper welding technology (=UTP philosophy):

- Weldability of component

- Metallurgical compatibility (alloying between base and filler metal)

- Wear characteristics of filler or coating material

- Change of base material due to welding/coating process (hardening, crack formation, like cold or hot cracking) 
- Change of filler/coating material due to dilution with base material

- Weld thermal Cycle dependent on preheating, interpass temperature, and cooling)

- Selection of welding or coating process technology according to technical and economic aspects

- Determination of proper process parameters

- Possibilities for mechanical post treatment

In case of cladding using Stellite, it is important to know the hardness at $500^{\circ} \mathrm{C}$ and not at room temperature [7]. Depending on the $\mathrm{W}$-content, several types are available. It is known that, due to hardness differences, Stellite 6 behaves better in case of forging presses compared to Stellite 21; the latter is better suitable for forging hammers.

It has been reported that plasma-nitriding is a favoured surface technology, whereby the best performance could be achieved without a white nitride layer. An optimal processing temperature is about 500 to $540^{\circ} \mathrm{C}$ [8]. There are trials using duplex layers in the sequence: nitriding plus PVD or CVD or PACVD [9, 10]. Due to economic reasons, these technologies are seldomly applied.

Repair cabins using automatic controlled welding robots are more interesting. The worn dies are scanned using laser scanning systems, and data are compared with the original design data.

Depending on the coordinate differences, a diode laser and filler powder are used for weld cladding. With a mechanical treatment using a 5-axis contour HSC milling, the final shape is given. A post weld heat treatment may be applied to reduce residual stresses.

\section{Conclusions}

- There is no single method which can be applied successfully to all cases.

- The choice of an optimal repair method is rather dependent on the understanding of the primary damaging mechanism, which is again dependent on various factors like hammer/press, shape complexity, local sliding speed, temperature at the interface, contact time, etc.)

- Counter measures can counteract each other, e.g. a hardness increase has a negative effect on toughness.

- A permanent documentation of actual processing conditions combined with a damage measurement can be significant to understand the vital phenomena, which are, of course, system dependent.

- Due to the fact that the extent of damage is locally different, the counter measures also need to be different depending on the location.

- Automatisation or mechanised repair cabins using robots can be good economical solutions for maintenance.

- The planned die life time has to be considered with respect to the batch size of the forging order.

Open access funding provided by Montanuniversität Leoben

Open Access This article is distributed under the terms of the Creative Commons Attribution 4.0 International License (http://creativecommons. org/licenses/by/4.0/), which permits unrestricted use, distribution, and reproduction in any medium, provided you give appropriate credit to the original author(s) and the source, provide a link to the Creative Commons license, and indicate if changes were made.

\section{References}

1. Doege, E.; Behrens, B.-A.: Handbuch Umformtechnik, Springer Verlag, 2007

2. Rahn, R.; Schruff, U.: Improved tool performance and cost control in the forging industry, Proceedings of the 8th International Tooling Conference, RWTH Aachen, 2-4.6.2009, 2009, pp 213-224

3. Mayerhofer, J.; Zinner, S.: Innovative Stähle für Schmiedewerkzeuge - vom Anforderungsprofil zur erfolgreichen Anwendung, in: Hrsg. Buchmayr, B.; Behrens, B. A. (eds): Proceedings of the Conference Schmiedewerkzeuge, 24.-25.10.2011, Salzburg, 2011, pp 117-135

4. Buchmayr, B.: Reparaturtechnologien - Übersicht der Möglichkeiten, Workshop Schmiedewerkzeuge, Conference Schmiedewerkzeuge, 24.-25.10.2011, Salzburg, 2011, pp 135ff.

5. Boardman, B.: Fatigue Resistance of Steels, in: ASM Handbook Vol.1, 1990, p.679

6. Yilkiran, T.; Behrens, B.-A.; Buchmayr, B.: Maßnahmen zur Reparatur und Lebensdauererhöhung von Schmiedewerkzeugen, SchmiedeJournal, März 2012, pp 52-57

7. Kashani, H.; Amadeh, A.; Ghasemi, H. M.: Room and high temperature wear behaviors of nickel and cobalt base weld overlay coatings on hot forging dies, Wear, 262 (2007), pp 800-806

8. Paschke, H.; Weber, M.; Kaestner, P.; Braeuer, G.: Influence of different plasma nitriding treatments on the wear and crack behavior of forging tools evaluated by Rockwell indentation and scratch tests, Surface \& Coating Technology, 205 (2010), pp 1465-1469

9. Navinsek, B.; Panjan, P.; Urankar, I.; Cvahte, P.; Gorenjak, F.: Improvement of hot-working processes with PVD coatings and duplex treatment, Surface \& Coating Technology, 142-144 (2001), pp 11481154

10. Leskovsek, V.; Podgornik, B.; Jenko, M.: A PACVD duplex coating for hot-forging applications, Wear, 266 (2009), pp 453-460 